changes in the treatment policy of the cardiac control unit during this period.

The fall in mortality was confined to those patients who had previously received insulin or oral hypoglycaemic drugs and did not occur in the group treated by diet. The reduction in the incidence of major complications was significant only in the group who had received oral hypoglycaemic drugs before admission. Oral hypoglycaemic drugs have several potentially deleterious effects in patients with coronary heart disease. Sulphonylureas have a positive inotropic action, which is generally disadvantageous in acute myocardial infarction, leading to increased myocardial consumption of oxygen and possibly increased infarct size. These agents may be harmful in myocardial infarction, and a change to insulin could therefore be of benefit. Biguanides are associated with the development of acidosis in stressful illnesses, including myocardial infarction, but none of our control patients showed evidence of this metabolic upset. Furthermore, a study by the University Group Diabetes Program found an increased cardiovascular mortality in patients receiving oral hypoglycaemic drugs. ${ }^{13}$ Although the design and conclusion of this study were criticised, ${ }^{14}$ a later review concluded that there was evidence of harmful effects from these agents. ${ }^{15}$

Our results differ from a recent study using a similar regimen in diabetics suffering from acute myocardial infarction. Gwilt et al found no improvement in mortality after changing to continuous intravenous infusion of insulin. ${ }^{16}$ The reasons for this difference are not clear. Our patients were of similar age and sex distribution and had similar blood glucose concentrations on admission, but they had a higher incidence of previous myocardial infarction.

Because of our mobile cardiac unit patients are admitted to hospital more rapidly than in units without this facility. It may be that, to be effective, the infusion of insulin has to be begun as early as possible in the course of acute myocardial infarction; this aspect requires further study.

In conclusion, we have shown a fall in mortality and compli- cations in diabetics treated with continuous intravenous infusion of insulin after an acute myocardial infarction. The effect on complications appears to be most noticeable in those who received oral hypoglycaemic drugs before admission. This was not a controlled trial, but such a trial is now under way. Nevertheless, as an observation of the effects of a change in treatment this study would indicate that such treatment should be considered in all diabetics suffering acute myocardial infarction.

\section{References}

1 Opie LH, Tansey MJ, Kennelly BM. The heart in diabetes mellitus. Part Acute myocardial infarction and diabetes. $S$ Afr Med $\mathcal{F} 1979 ; 56: 256-61$.

2 Vigorito C, Betocchi S, Bonzani G, et al. Severity of coronary artery disease in patients with diabetes mellitus. Angiographic study of 34 diabetic and 120 pan-diabetic patients. Am Heart $\mathcal{F} 1980 ; 100: 782-7$.

3 Regan TJ, Lyons MM, Ahmed SS, et al. Evidence for cardiomyopathy in familial diabetes mellitus. $\mathcal{f}$ Clin Invest $1977 ; 60: 885-99$.

4 Hamby RI, Zoneraich S, Sherman L. Diabetic cardiomyopathy. FAMA 1974;229 $1749-54$

Shapiro $M$. A prospective study of heart disease in diabetes mellitus. $Q \mathcal{F} \mathrm{Med}$

1984;53:55-68.
Benedict CR, Grahame-Smith DG. Plasma adrenaline and noradrenaline concentrations and dopamine- 3 -hydroxylase activity in myocardial infarction with centrations and dopamine- $\beta$-hydroxylase activity in myocardial infarction with
and without cardiogenic shock. Br Heart $\mathcal{f} 1979 ; 42: 214-20$.
Bailey RR, Abernethy MH, Beaven DW. Adrenocortical response to the stress of

an acute myocardial infarction. Lancet $1967 ; 1: 970-3$.

8 Liedtke AJ. Alterations of carbohydrate and lipid metabolism in the acutely ischemic heart. Prog Cardiovasc Dis 1981;23:321-36.

Oliver MF, Kurien VA, Greenwood TW. Relation between serum free fatty acids and arrhythmias and death after acute myocardial infarction. Lancet 1968;

$10 \mathrm{Vik}-\mathrm{Mo} \mathrm{H}_{\mathrm{H}} \mathrm{Mjos} \mathrm{D}$. Influence of free fatty acids on myocardial oxygen consump-

11 Gwilt DJ, Nattrass M, Pentecost BL. Use of low dose insulin infusions in diabetics after myocardial infarction. Br Med f 1982;285:1402-4.

12 Dalby AJ, Bricknell OL, Opie LH. Effect of glucose-insulin-potassium infusion on epicordial ECG changes and on myocardial metabolic changes after coronary artery ligation in dogs. Cardiovasc Res 1981;15:588-98.

13 University Group Diabetes Program. A study of the effects of hypoglycemic agents on vascular complications in patients with adult-onset diabetes. II. Mortality results. Diabetes 1970;19 (suppl 2):785-830

14 Feinstein AR. Clinical biostatistics. XXXV. The persistent clinical failures and allacies of the UGDP study. Clin Pharmacol Ther 1976;19:79-93.

15 Committee for the Assessment of Bioactive Aspects of Controlled Trials of Hypo-

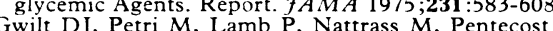

Gwilt DJ, Petri $M$, Lamb $P$, Nattrass $M$, Pentecost BL. Effect of intravenous insulin infusion on mortality among
farction. Br Heart $\mathcal{f} 1984 ; \mathbf{5 1}: 626-31$.

\title{
Early gastric cancer: the case for long term surveillance
}

\author{
P W J HOUGHTON, N J MCC MORTENSEN, A ALLAN, R C N WILLIAMSON, J D DAVIES
}

\begin{abstract}
Thirty five patients with early gastric cancer have been treated at the Bristol Royal Infirmary since 1965. The number of cases diagnosed has doubled in the last 10 years. Epigastric pain $(74 \%)$, loss of weight $(63 \%)$, and gastrointestinal bleeding $(\mathbf{4 3} \%)$ were the most common presenting symptoms, with a median length of history of 12 months (range five days to 72 months). Life table survival curves showed a crude five year survival of $71 \%$ (age adjusted $92 \%$ ) and a crude 10 year survival of $63 \%$ (age adjusted $85 \%$ ). Sixteen patients have been followed
\end{abstract}

\footnotetext{
University Departments of Surgery and Pathology, Bristol Royal Infirmary, Bristol BS2 $8 \mathrm{HW}$

P W J HOUGHTON, FRCS, research fellow

N J MCC MORTENSEN, MD, FRCS, consultant senior lecture

A ALLAN, MD, FRCS, registrar

R C N WILLIAMSON, MCHIR, FRCS, professor of surgery

J D DAVIES, MD, FRCPATH, consultant senior lecturer

Correspondence to: $\mathrm{Mr}$ Houghton.
}

up clinically, endoscopically, and by scintigraphy with technetium-99m p-butyl iminodiacetic acid to assess the risk of recurrent disease. Of seven patients with pronounced bile reflux, two had moderate dysplasia of the gastric remnant, and one patient was found to have developed a metachronous tumour nine years after surgery.

Partial resection seems to be the best choice of treatment for early gastric cancer, giving good functional results. Consideration should, however, be given to Roux en $Y$ diversion, and long term surveillance of the gastric remnant is recommended.

\section{Introduction}

In 1938 Saeki identified a subgroup of patients with gastric cancer of limited depth of invasion who had a $90 \%$ five year survival. ${ }^{1}$ In 1962 the Japanese Endoscopic Society defined this adenocarcinoma confined to the gastric mucosa or submucosa with or without lymph node metastases as "early gastric cancer." In recent years the prevalence of early gastric cancer in the Western world has risen. Between 1960 and 1969 less than 1\% 
of gastric carcinomas were early gastric cancers $^{3} 4$ but more recent studies have shown that the Western incidence of early gastric cancer is now between $10 \%$ and $16 \%{ }^{45}$ This rise is belatedly mirroring a similar increase in Japan, where, as a result of routine screening, the incidence of early gastric cancer is now over $30 \%$ of all gastric cancers. ${ }^{6}$ Despite the increase in early gastric cancer the number of cases reported in most Western series remains small, and there has been little information on the long term follow up of these patients. ${ }^{4-8}$ In 1976 the early experience of early gastric cancer in this institution was described. ${ }^{10}$ This paper describes the long term follow up of those cases and more recent cases seen here until 1984.

\section{Patients and methods}

The pathology records of all patients with gastric cancer since 1965 were consulted and the case notes of those with a diagnosis of early gastric cancer were retrieved. A consultant pathologist re-examined the histological sections to confirm the initial diagnosis. There were 14 women and 21 men with a median age of 67 (range 44 to 79). Twelve patients $(34 \%)$ were over the age of 70 and, of those, eight patients $(23 \%)$ were over 75 . All surviving patients who were no longer attending outpatient clinics and those still under review were invited to attend our gastric follow up clinic. Patients were examined and assessed clinically by Visick grading. " Sixteen patients consented to undergo gastroscopy, biopsy, and scintigraphy using technetium- $99 \mathrm{~m} p$-butyl iminodiacetic acid, to assess radiologically the degree of postoperative duodenogastric reflux.

\section{Results}

Between 1965 and 197412 patients were diagnosed as having early gastric cancer after detailed examination of gastric resections. ${ }^{12}$ Since 1975 a further 23 cases of early gastric cancer have been diagnosed, an increase of almost $100 \%$ on the previous decade. The symptoms of patients who presented with early gastric cancer are shown in table I. Seventy seven per cent of the patients were referred

TABLE I-Presenting symptoms in cases of early gastric cancer

\begin{tabular}{|c|c|c|c|}
\hline Symptom & $\begin{array}{l}\text { No ( }\left({ }^{\circ}\right) \\
\text { of cases }\end{array}$ & Symptom & $\begin{array}{l}\text { No }(0 \%) \\
\text { of cases }\end{array}$ \\
\hline $\begin{array}{l}\text { Epigastric pain } \\
\text { Heartburn } \\
\text { Anorexia } \\
\text { Loss of weight } \\
\text { Nausea or vomiting }\end{array}$ & $\begin{array}{r}26(74) \\
4(11) \\
8(23) \\
22(63) \\
9(26)\end{array}$ & $\begin{array}{l}\text { Melaena } \\
\text { Haematemesis } \\
\text { Anaemia } \\
\text { History of peptic ulcer }\end{array}$ & $\left.\begin{array}{l}8 \\
5 \\
5 \\
7\end{array}\right\} 15(20)$ \\
\hline
\end{tabular}

directly by their general practitioners, and $23 \%$ were already undergoing investigation for other conditions. The length of history ranged from five days to 72 months (median 12 months) and the time from referral to histological diagnosis ranged from five days to 25 months (mean time 1.5 months).

\section{DIAGNOSIS}

Twenty six patients had at least one barium meal (range 1-3, mean 1.36) and five patients had this examination alone, all before the routine use of endoscopy. Twenty one lesions were seen on barium meal studies, but not all were thought to be malignant by the radiologist. Five lesions were missed, including one double lesion, a false negative rate of $19 \%$. Thirty patients had at least one gastroscopy (range 1-7, mean 1.8 examinations). Twenty nine lesions were detected visually, but again not all were initially thought to be malignant. Eleven patients underwent biopsy only, 18 biopsy and cytological brushing, and one neither. The number of biopsy specimens taken varied from one to eight. Fifty one per cent of all the biopsy and cytology specimens taken were negative. One tumour was completely missed by endoscopy and only found by repeat barium meal, giving an endoscopic rate of detection of $96 \%$.

\section{SURGERY}

A wide range of operations was performed (table II), reflecting the frequent uncertainty of the diagnosis and the unfamiliarity of the surgeon with the condition. Three total gastrectomies were performed, one for an early gastric cancer high on the lesser curve, one in a man with a double lesion, and one was a residual gastrectomy for an early gastric cancer in the Polya stump of a man who had had a gastric

TABLE II-Surgical procedures performed in 35 cases of early gastric cancer

\begin{tabular}{lclc}
\hline Procedure & $\begin{array}{c}\text { No of } \\
\text { cases }\end{array}$ & Procedure & $\begin{array}{c}\text { No of } \\
\text { cases }\end{array}$ \\
\hline $\begin{array}{l}\text { Local resection } \\
\text { Ivor Lewis operation }\end{array}$ & 1 & Billroth I & 8 \\
Total gastrectomy & 1 & Radical Billroth I & 9 \\
Proximal gastrectomy & 1 & Polya gastrectomy & 2 \\
Roux en Y diversion & 3 & Nodical Polya gastrectomy & 6 \\
\hline
\end{tabular}

ulcer excised 27 years previously. The Ivor Lewis operation was for a lesion which arose in a Barrett's ulcer in a hiatus hernia and was particularly difficult to diagnose. Eight of the elderly patients (over 70 ) had a Billroth I operation $\left(66^{\circ}{ }_{0}^{\prime}\right)$, two had Polya gastrectomies, and one had a Roux en Y diversion. The remaining elderly patient only had a local resection for what was thought to be a benign polyp, the diagnosis being established by histological examination after her operation. Unfortunately, she could not be traced, although her death had not been recorded by the Registrar General.

\section{PATHOLOGY}

The pathological classification of early gastric cancer is now well established..$^{13}$ All the lesions were single apart from one, which was double. Twenty $(57 \%)$ were intramucosal and $15(43 \%)$ submucosal. No patient with cohesive lymph node metastases was included in the study. One patient had micrometastases consisting of scattered cells in the paragastric lymph nodes. Fourteen lesions were situated in the lesser curve, 17 around the pylorus and antrum, three in the main body, one in the cardia, and one was peristomal. There were 10 cases of type I early gastric cancer, three of type IIa, one of type b, five of type c, four of type IIc and type III combined, and 13 of type III. Examination of the resected stomach showed that 27 patients $(77 \%)$ had associated premalignant conditions, ${ }^{14}$ including atrophic gastritis in 13, intestinal metaplasia in 15, and dysplasia in eight. Other risk features included one previous resection for peptic ulcer disease and a history of gastric ulceration in 11 patients. Eight patients (23\%) had or have since developed other neoplasms, including carcinoma of the bronchus in two, squamous cell carcinoma in one, glioma in one, myeloma in two, carcinoma of the rectum in one, and carcinoma of the breast in one.

\section{SURVIVAL}

Follow up was from six months to 13 years, with a median time of 3.5 years. One patient was lost to follow up, 21 are alive, and 13 have died. One patient who was diagnosed after biopsy as having early gastric cancer was considered too unfit for surgery as a chest radiograph suggested carcinoma of the bronchus. Treatment with cimetidine resulted in his ulcer healing and he is being followed up with interest, the ulcer remaining healed at six months. There were two immediate postoperative deaths, one after a total gastrectomy in the patient with two lesions, and the other from a stroke after a Polya gastrectoriy in an elderly man. Only two patients have died of known recurrence. A further two patients may have died from recurrence, one having had a carcinoma of the rectum excised nine years previously. Seven others have died of causes not related to their early gastric cancer. Excluding the two immediate postoperative deaths, life table survival curves (see figure) show a crude five year survival of $71 \%$ (age adjusted $92 \%$ ) and a 10 year survival of $63 \%$ (age adjusted $85 \%$ ).

Sixteen patients have undergone gastroscopy and scintigraphy using ${ }^{99 \mathrm{~m}}$ Tc $p$-butyl iminodiacetic acid. The mean time from operation to endoscopy was 1.5 years, range six months to nine years. Seven patients had bile reflux and gastritis at gastroscopy and in one case this was severe. Chronic gastritis was confirmed by histological 


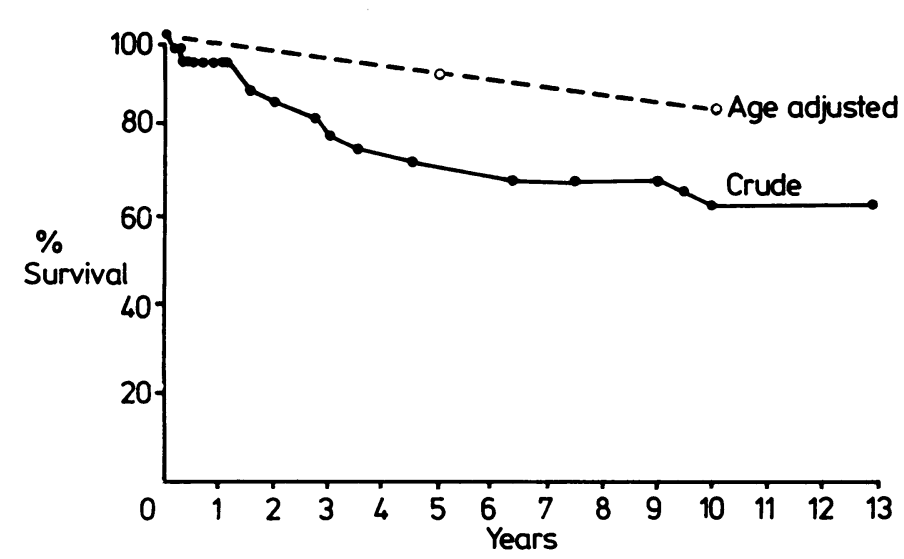

Life table survival curves in 35 patients with early gastric cancer, excluding immediate postoperative deaths.

examination in four of these patients. Atrophic gastritis was found in two patients and intestinal metaplasia in three. Two cases of moderate dysplasia were identified and one patient was found to have developed an asymptomatic metachronous early gastric cancer in his gastric stump nine years after a Polya gastrectomy for early gastric cancer. He underwent a total gastrectomy and one year after the operation remains well. Scintigraphy using ${ }^{99 \mathrm{~m}}$ Tc p-butyl iminodiacetic acid in 16 patients showed grade 3 reflux (severe) in eight, all of whom had had either a Billroth I or Polya gastrectomy. Those who had Roux en Y diversions had minimal bile reflux, although one patient required a later revision because of ischaemic stenosis of his Roux loop. Functional results were good and Visick grades at clinical examination were $I$ in 13 patients, II in two patients, and III in one.

\section{Discussion}

In 1976 Machado et al suggested that early gastric cancer was probably underdiagnosed in the United Kingdom. ${ }^{10}$ Since then the incidence of early gastric cancer has risen throughout the Western world, and in our hospital the number of cases diagnosed has almost doubled in 10 years. This reflects an increased awareness of early gastric cancer as a clinical entity, and improvements in endoscopic techniques such as multiple biopsies and cytological brushing, 815 which, combined, can give a diagnostic accuracy in upper gastrointestinal lesions as high as $95 \% .{ }^{16}$ Despite these advances, however, the diagnosis of early gastric cancer remains difficult. In our patients the clinical picture was often confused by previous dyspepsia, especially in the $20 \%$ of patients with a history of gastric ulceration. The diagnosis of malignancy was made on the first endoscopy in only 18 out of 30 patients $(60 \%)$, 12 patients requiring multiple gastroscopies, although all but one of the lesions were seen visually. With further advances in endoscopic techniques such as dye scattering ${ }^{17}$ we may hope to increase the diagnostic yield and perhaps identify these lesions sooner. Barium meal examination alone was not satisfactory, with a false negative rate of $19 \%$ in our series.

The long history of patients with early gastric cancer is similar to that reported in other series. ${ }^{3} 58$ Unlike these workers, however, we found a much higher incidence of weight loss $(63 \%)$, confirming the findings of Rosch, who reported that almost two thirds of his patients had lost weight (W Rosch, paper read at second British Society of Gastroenterology/Smith Kline and French international workshop 1981). Gastrointestinal bleeding and anaemia were also surprisingly common (43\%) in view of the fact that the lesions were often small. It is now known that early gastric cancer can grow very slowly and that many years can elapse before progression to advanced gastric cancer. ${ }^{18}$ One patient had been treated for four years with cimetidine before the diagnosis was eventually established. These findings emphasise the need for a high index of suspicion in all patients over 50 years of age complaining of persistent dyspepsia and having a history of gastric ulceration.
The correct surgical management of early gastric cancer remains controversial. A minority of surgeons advocate total gastrectomy, arguing that early gastric cancer can be multifocal and that the potential risk of conditions such as achlorhydria and bile reflux is increased after partial resection ( $H \mathrm{~J}$ Meyer, R Pichlomayr, paper read at second British Society of Gastroenterology/Smith Kline and French international workshop 1981). Total gastrectomy, however, may carry a high mortality in this condition, ${ }^{3}$ and one of the two postoperative deaths in this series was in the patient with two lesions who had a total gastrectomy. The role of surgery in the elderly high risk patient with early gastric cancer is also contentious. In our elderly patients there was one postoperative death after partial gastrectomy, giving a $9 \%$ mortality. Since the clinical course of the early gastric cancer may be one of some years ${ }^{18}$ endoscopic treatment with either polypectomy or argon laser photocoagulation might be a suitable alternative, ${ }^{19}$ although this is an area which requires further evaluation. The recurrence rate in Japan is $3-6 \% \%^{20}$ and seems higher in the West at around $13-20 \% .^{35}$ In our patients there were two known recurrences 3.5 and 4.5 years after partial resection. If two more possible cases are included, this gives a recurrence rate of $11 \%$. There was also a metachronous early gastric cancer arising nine years after resection. Roux en $Y$ biliary diversion was performed in three patients and this has the advantage of reducing enterogastric reflux, which may promote gastric mucosal changes. ${ }^{22}$ Patients with carcinomas are known to have a greater risk of developing further tumours ${ }^{23}$ and this phenomenon has been reported with early gastric cancer. ${ }^{21}$ In our series $23 \%$ of patients have had associated neoplasms with four deaths related to tumours. The five year and 10 year survival curves of our patients, although less than those reported from Japan, are encouraging and comparable with Western series. ${ }^{3} 8$ The increased risk of stump cancer after partial resection is well known, ${ }^{24} 25$ but the value of long term, endoscopic follow up in patients with early gastric cancer is less certain. ${ }^{26} 27$ Sixteen of our patients have been subjected to close follow up in order to assess the risk of recurrent disease in the gastric remnant. Seven patients $(44 \%)$ showed endoscopic and radiological evidence of bile reflux. Multiple gastric biopsies showed gastric mucosal changes in $43 \%$ of patients, but no mucosal changes were apparent in the three patients who had Roux en $Y$ procedures. We would therefore advocate endoscopic follow up for patients with early gastric cancer having a partial resection, perhaps at yearly intervals. Good functional results were obtained with partial resection and this would therefore appear to be the appropriate operation for early gastric cancer, bearing in mind our $33 \%$ mortality for total gastrectomy. Consideration should be given to Roux en $\mathrm{Y}$ diversion as this reduces bile reflux into the gastric remnant.

Although the incidence of gastric cancer is declining throughout the world ${ }^{28}$ it still remains the fourth most common cancer in England and Wales (J W L Fielding, paper read at second British Society of Gastroenterology/Smith Kline and French international workshop 1981). The proportion of early gastric cancers is, however, rising, and with its excellent prognosis it is to be hoped that early gastric cancer will be increasingly recognised, ${ }^{18}$ with a corresponding improvement in overall survival rates. With increasing numbers of long term survivors an endoscopic follow up policy will be necessary.

We thank the surgeons and physicians of the Bristol Royal Infirmary for allowing us to study patients under their care, and $\mathrm{Mr} \mathrm{A} \mathrm{O}$ Hughes for his statistical advice. P W J Houghton is funded by the Cancer Research Campaign.

\section{References}

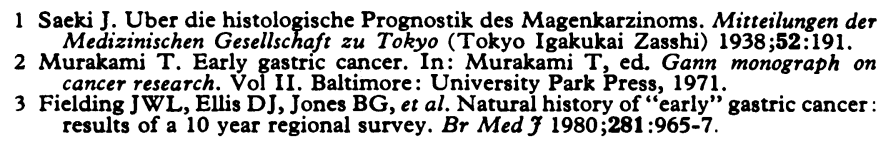


4 Evans DMD, Craven J L, Murphy F, Cleary BK. Comparison of "early gastric cancer" in Britain and Japan. Gut 1978;19:1-9.

5 Carter KJ, Schaffer HA, Ritchie WP. Early gastric cancer. Ann Surg 1984;199:

6 Muto $M$, Maki T, Majima S, Yamaguchi I. Improvement in the end-results of surgical treatment of gastric cancer. Surgery 1968;63:229-35.

7 Kaneko E, Nakamura T, Umeda N, Fuino M, Niwa H. Outcome of gastric carcinoma detected by gastric mass survey in Japan. Gut $1977 ; 18: 626-30$.

Eancer. Gastroenterology $1981 ; 81: 247-56$

carcinoma Gut 1976:17:41-7.

achado G, Davies JD, Tudway AJC, Salmon PR, Read AE. Superficial carci-
noma of the stomach. Br Med 7 1976;ii:77-9. B

of the failures after gastrectomy. Ann $R$ Coll Surg Engl 1948

12 Davies JD, Tudway AJC, Roberts G, Machado G. Detection of superficial gastric carcinoma in biopsies and resected stomachs. F Clin Pathol 1976;29

3 Murakami T. Pathomorphological diagnosis. Definition and classification of early gastric cancer. In: Murakami T, ed. Early gastric cancer, Gann monograph on
cancer research II. Tokyo: University of Tokyo Press, 1971:53-5.

14 Morson BC, Sobin LH, Grundmann E, Johansen A, Nagayo T, Serk-Hanssen A. Precancerous conditions and epithelial dysplasia in the stomach. $\mathcal{F}$ Clin Pathol 1980;33:711-21.

15 Kobayashi S, Kasugi T. Brushing cytology for the diagnosis of gastric cancer involving the cardia or the lower oesophagus. Acta Cytol 1978;22:155-61.

16 Mortensen NJMcC, Mackenzie EFD. Accuracy of oesophageal brush cytology: results of a prospective study and multicentre slide exchange. Br $\mathcal{F}$ Surg 1981; the upper part of the stomach by the endoscopic Congo red-methylene blue test. Endoscopy 1984;16:131-4.

18 Tsukuma H, Mishima T, Oshima A. Prospective study of "early" gastric cancer.

Int $\mathcal{F}$ Cancer $1983 ; 31: 421-6$.
19 Rosch W, Fruhmorgen P. Endoscopic treatment of precancerous and early gastric carcinoma. Endoscopy 1980;12:109-13.

20 Murakami T. Early cancer of the stomach. World f Surg 1979;3:685-92.

Koga S, Kaibara N, Tamura $\mathrm{H}$, Nishidoi $\mathrm{H}$, Kimura $\mathrm{O}$. Cause of late postoperative death in patients with early gastric cancer with special reference to Surgery 1984;96:511-6.

22 Thomàs WEG, Cooper MJ, Mortensen NJMcC, Burton PA, Davies ER. The clinical assessment of duodenogastric reflux by scintigraphy and its relation to histological changes in gastric mucosa. Scand $\mathcal{f}$ Gastroenterol 1984;19 (suppl 92):195-9.

23 Warren S, Gates C. Multiple primary malignant tumors. A study of the literature and a statistical study. American fournal of Cancer 1932;16:1355-414. 24 Domellof L, Janunger KG. The risk for gastric carcinoma after partial gastrectomy. Am ₹ Surg 1977;134:581-4.

25 Schrumpf E, Serck-Hanssen A, Stadaas J, Aune S, Myren J, Osnes M. Mucosal changes in the gastric stump 20-25 years after partial gastrectomy. Lancet 1977 ;ii :467-9.

26 Farrands PA, Blake JRS, Ansell ID, Cotton RE, Hardcastle JD. Endoscopic review of patients who have had gastric surgery. Br Med 7 1983;286:755-8. 27 Mortensen NJMcC, Thomas WEG, Jones SM, Savage A. Endoscopic screening for premalignant changes 25 years after gastrectomy: results of a five-year $28 \mathrm{Muir} C \mathrm{C}$, Parkin DM. The world cancer burden: prevent or perish. Br Med $\mathcal{F}$
$1985 ; \mathbf{2 9 0}: 5-6$.

(Accepted 9 May 1985)

\author{
M C ORMISTON, M T J SEYMOUR, G E VENN, R I COHEN, J A FOX
}

\begin{abstract}
Cadexomer iodine (Iodosorb) is a hydrophilic starch powder containing iodine, which is a suitable dressing for granulating wounds such as venous ulcers. A total of 61 outpatients with chronic venous ulcers participated in a randomised optional crossover trial using cadexomer iodine or a standard dressing for their ulcers. The trial lasted for 24 weeks or until the ulcer had healed. Two patients withdrew during the course of the trial. Both treatments were highly effective, but the epithelium of ulcers dressed with cadexomer iodine grew again significantly faster $(p<0.001)$. At the midpoint of the trial (12th week) 13 of 30 patients receiving standard treatment were changed to cadexomer iodine, while only three of 29 receiving cadexomer iodine changed to the standard dressing $(p<0.02)$. In most cases ulcers were dressed and rebandaged daily by the patients themselves after instruction and supervision. This may be better than having dressings and bandages applied by professionals less regularly.
\end{abstract}

\section{Introduction}

Chronic venous ulcers occur in $1-3 \%$ of the population ${ }^{1}$ and present a relapsing or intractable problem that places a heavy demand on nursing and medical resources. A well applied compression bandage is the mainstay of treatment in ambulant patients. Though numerous local dressings are available, there have been few controlled trials that compare them. ${ }^{2-4}$

Cadexomer iodine (Iodosorb, Perstorp AB and Stuart Pharmaceuticals Ltd) is a strongly hydrophilic starch polymer

Edgware General Hospital, Edgware, Middlesex

M C ORMISTON, FRCS, surgical registrar

$M$ T J SEYMOUR, FRCS, surgical senior house officer

G E VENN, FRCS, surgical registrar

R I COHEN, $M B$, BS, general practitioner

J A FOX, FRCS, consultant surgeon

Correspondence to: Mr M C Ormiston, University College Hospital, London W1. powder with iodine incorporated within its matrix. It absorbs exudate and particulate matter from the surface of granulating wounds. As it becomes moist the iodine is released. Thus it is designed to clean the wound and, at the same time, exert a bactericidal action. Furthermore, it can be washed off without disturbing delicate new epithelium when the wound is dressed. Once saturated it is no longer effective, so wounds must be redressed regularly.

In an international multicentre study cadexomer iodine was compared with various local favourite dressings in treating chronic venous ulcers. ${ }^{3}$ The preliminary results of the study carried out in this hospital have already been presented, ${ }^{5}$ and we now analyse the results in 61 patients.

\section{Patients and methods}

Outpatients with chronic venous ulcers that had not healed for at least three months were asked to participate in the study. In all cases a medical history was taken and a physical examination, including Doppler ankle pressure index, performed. A full blood count, erythrocyte sedimentation rate, Wasserman reaction, blood glucose concentration, tests of liver function, and analysis of urine were carried out. Almost all patients selected were capable of dressing and bandaging their own ulcers. In the few exceptional cases a relative or nurse was available to dress the ulcer. Patients were excluded from the study if there was clinical or laboratory evidence that their ulcer was of non-venous aetiology. Particular care was taken not to include patients with peripheral vascular disease suggested by examination or a pressure index of the dorsalis pedis or posterior tibial to brachial artery of less than $0 \cdot 70$. Patients in whom compliance was expected to be poor due to concomitant physical or mental disability or travelling problems were also excluded from the study.

At the first visit the size and appearance of the ulcer were recorded by outline tracing, planimetry, and photography. Bacterial culture swabs were taken. Subjective criteria including pain, oedema, erythema, exudate, slough, and the proportion of the surface of the ulcer covered by granulation tissue were recorded on linear scales (0-100). Pain was assessed by the patient and the other criteria by the same observer at each visit. Patients were then allocated a code number according to the sequence of selection for the trial. For each number there was a double sealed envelope that contained a paper stating which treatment the patient should receive. The sequence of treatments was randomised, and the code of randomisation was not available to the investigators. The comparative treatments were cadexomer iodine or a standard 